Military Technical College Kobry El-Kobbah, Cairo, Egypt

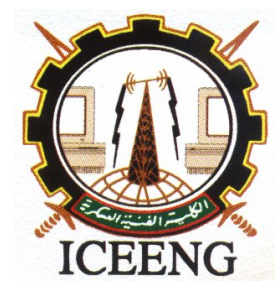

$7^{\text {th }}$ International Conference on Electrical Engineering ICEENG 2010

\title{
Performance Enhancement for Dual-band Circularly \\ Polarized Patch Antenna using Under-slot EBG Structure
}

\author{
By
}
M. Salama*
A. El-Tager**
A. Mamdouh**
M. A. Eleiwa**

\section{Abstract:}

In this paper, a novel circularly polarized, dual-frequency, slotted square patch is designed, implemented and measured. This patch is designed by applying electromagnetic band-gap (EBG) structures in the ground plane under the slots with probe feeding mechanism to operate at $2.25 \mathrm{GHz}$ and $3 \mathrm{GHz}$. Five different schemes of periodic defects are applied to its ground plane and compared using $3 \mathrm{D}$ EM simulation. The one with periodic etched circles under the dual frequency slots is found to be the best. Hence, a parametric analysis is performed to obtain the optimum values of the antenna physical dimensions. It exhibits superior performance enhancement compared to the same antenna that was designed and optimized without applying EBG structure. The enhancement in its performance is noticed as higher gain, wider bandwidth, better VSWR and axial ratio, without degrading any other parameter. Measurements are in good agreement with simulations, which verifies the design procedure and strongly recommends the proposed element for telemetry, telecommand and control (TT\&C) satellite antenna systems.

\section{Keywords:}

Dual-Band Antenna, Circular polarization, Electromagnetic Band gap, TT\&C Satellite antenna systems.

* Signal Department, Egyptian Armed Forces.

** Electronic Engineering Department, Military Technical College, Cairo, Egypt. 


\section{Introduction:}

A common property of most microstrip antennas is that the antenna element launches surface wave modes, in addition to the fields radiated into the space. The excitation of the surface waves lowers the overall radiation efficiency of the antenna. For finite-size substrates, the surface power will diffract from the edges of the substrates, resulting in a disturbance of the radiation pattern. The excitation of the surface waves also results in increased mutual coupling between distant antenna elements. For these reasons the excitation of surface waves is generally undesirable.

As a patch antenna radiates, a portion of the total available power for direct radiation becomes trapped along the surface of the substrate. This trapped electromagnetic energy leads to the development of surface waves. In fact, the ratio of power that radiates into the substrate compared to the power that radiates into air is approximately $\left(\varepsilon_{\mathrm{r}}^{3 / 2}: 1\right)$ [1]. This is governed by the rules of total internal reflection, which state that any field line radiated into the substrate at angles greater than the critical angle $\left(\theta_{\mathrm{c}}=\sin ^{-1}\left(\varepsilon_{\mathrm{r}}^{-1 / 2}\right)\right)$ is totally internally reflected at the top and bottom surfaces. This is illustrated in Figure 1. Thus a monolithic integrated dipole on GaAs substrate $\left(\varepsilon_{\mathrm{r}}=12.8\right)$ radiates 46 times more power into the substrate this occurs at $\theta_{\mathrm{c}}=16^{\circ}$, so that in many antenna structures the vast majority of the radiated power is trapped in the substrate, as shown in Figure 1 [1].

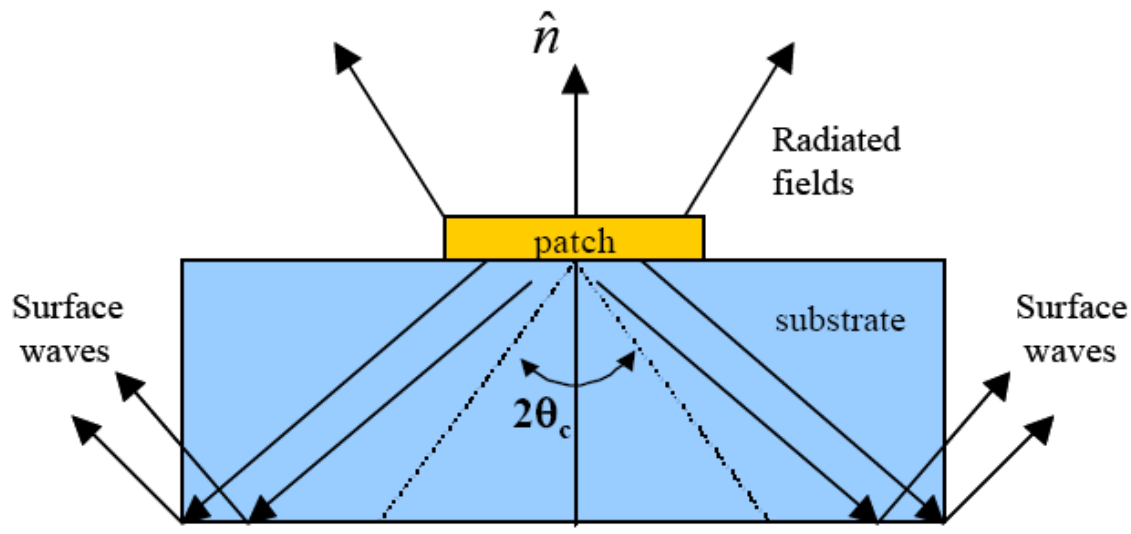

Figure (1): Field lines radiating from a patch antenna; illustrates the formation of surface waves

A recently developed method for improving the bandwidth and efficiency of a patch antenna is the insertion of a photonic crystal array into the substrate. Photonic crystals (PC) or EBG are a class of periodic dielectric, metallic, or composite structures that when introduced to an electromagnetic signal can exhibit a forbidden band of frequencies (or bandgap) in which the incident signal destructively interferes and thus is unable to propagate. If photonic crystals are inserted into the substrate of a patch antenna, then a broadband response can be obtained from this inherently narrowband antenna. This will result in improvements in the radiation characteristics of the patch antenna, by reducing pattern sidelobes and improving front-to-back pattern ratios and overall efficiency. 
Suppression or reduction of surface waves improves antenna efficiency and reduces side lobe level that is caused by the diffraction of surface waves at the edges of the antenna substrates. Surface diffraction plays a major role when thick substrates are used to improve the bandwidth of the antenna. A periodic defect structures in the ground plane with band-stop characterization can reduce surface waves and hence improve the overall antenna performance. This may be classified under the broad terminology of electromagnetic bandgap (EBG) [2]. EBG has been used to improve the performance of the antenna. In [3-5], a microstrip patch antenna with etched EBG on the ground plane was presented. In [6], a uniplanar compact bandgap substrate was applied to an aperture-coupled patch antenna. Also, a microstrip patch antenna with photonic band gap (PBG) substrate and high-impedance surface was reported in [7]. In this paper, different EBG structures are applied and compared to obtain the most suitable structure for this case. Then, a parametric analysis is performed for the under slot EBG structure to predict optimum dimensions.

\section{$\underline{\text { 2. Design and Simulation: }}$}

Nowadays, many applications require low-profile, low weight, dual frequency antennas. One of these applications is the telemetry, telecommand and control (TT\&C) antenna for satellite spacecrafts. Thus a circularly polarized, dual-frequency, slotted square patch was designed with probe feeding mechanism to operate as a (TT\&C) array element [8]. It has two narrow slots etched close to the radiating edges. Therefore, the $\mathrm{TM}_{100}$ mode is perturbed a little, whereas significant perturbation occurs for $\mathrm{TM}_{300}$ mode. Because perturbed $\mathrm{TM}_{300}$ mode has a radiation pattern similar to that of $\mathrm{TM}_{100}$ mode, the excitement of the two modes results in the dual band operation of the antenna. For producing circular polarization, the square patch must have four slots at the edges and a slot at the center. The geometric parameters of the antenna of [8] are illustrated in separate figures as shown in Figure 2. In this paper, the optimized antenna of [8] is taken to be the reference patch without applying any EBG structures as shown in Figure 3(a).

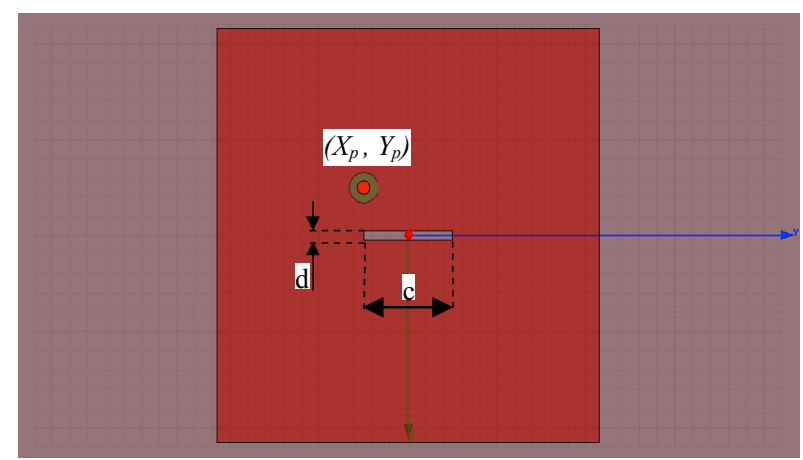

(a) Circular polarized (CP) central slot

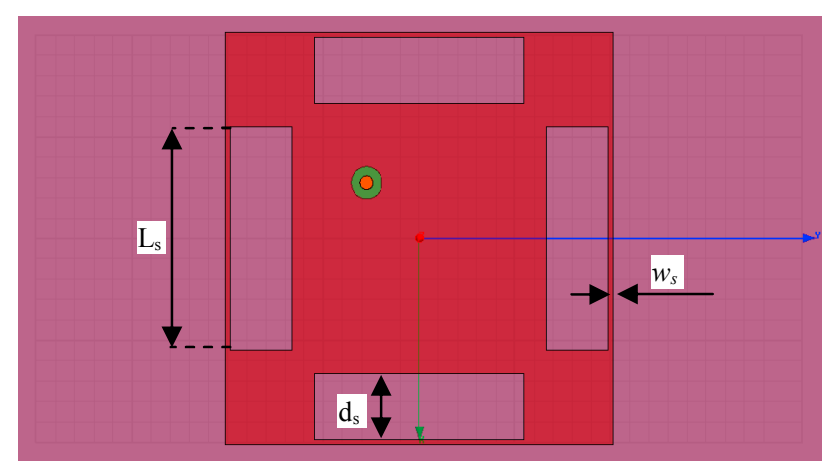

(b) Slotted square-patch antenna

Figure(2): Main geometric parameters of the antenna of [8] 
A low-loss teflon substrate with $\varepsilon_{\mathrm{r}}=2.2$ and $\mathrm{h}=1.6 \mathrm{~mm}$ was employed and the dualfrequency circularly polarized patch antenna at $\mathrm{f}_{100}=2.25 \mathrm{GHz}$ and $\mathrm{f}_{300}=3 \mathrm{GHz}$. The final optimized physical parameters were: $\mathrm{W}=\mathrm{L}=40.6 \mathrm{~mm}, X_{P}=Y_{P}=6 \mathrm{~mm}, L_{s}=19 \mathrm{~mm}$, $\mathrm{d}_{\mathrm{s}}=6.5 \mathrm{~mm}, \mathrm{w}_{\mathrm{s}}=0.5 \mathrm{~mm}, \mathrm{c}=10 \mathrm{~mm}, \mathrm{~d}=1 \mathrm{~mm}$.

Though the prototype of this patch is almost matched with simulations, it still needs several modifications to act as an array element for a (TT\&C) satellite antenna. In this paper, the enhancement of its axial ratio, HPBW gain and dual bandwidths is studied and applied. For the sake of this target, different EBG 1D and 2D planar structures are etched on the ground plane, analyzed, compared and optimized to enhance the antenna parameters.

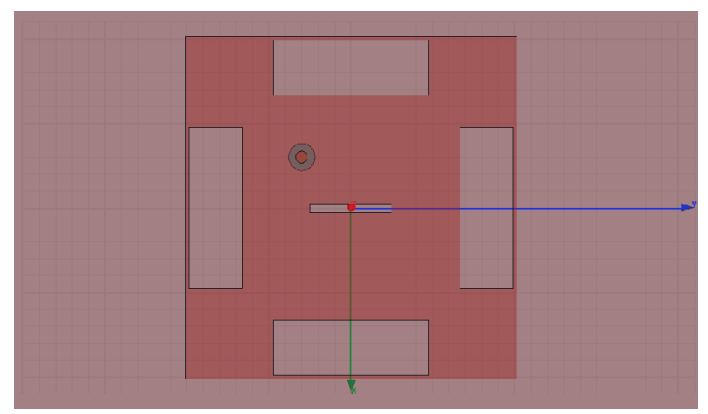

(a)

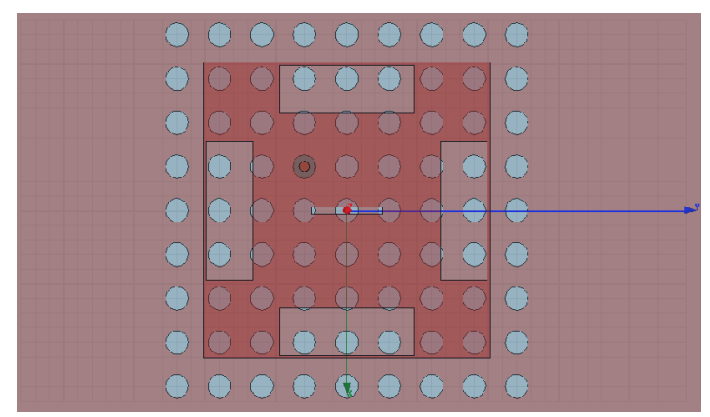

(c)

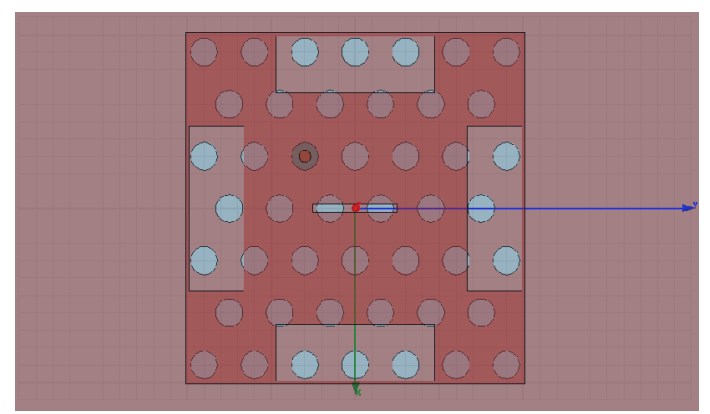

(e)

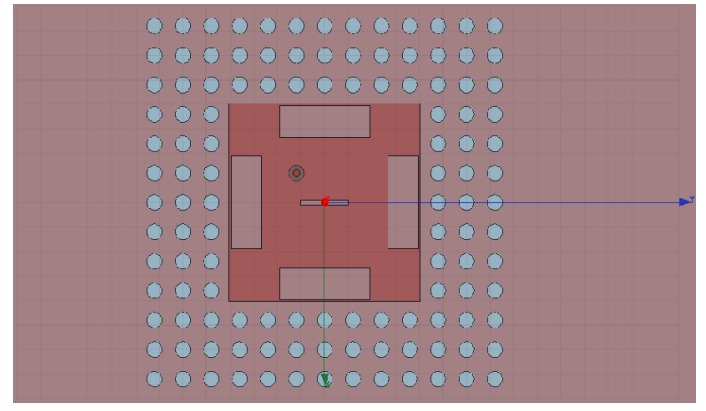

(b)

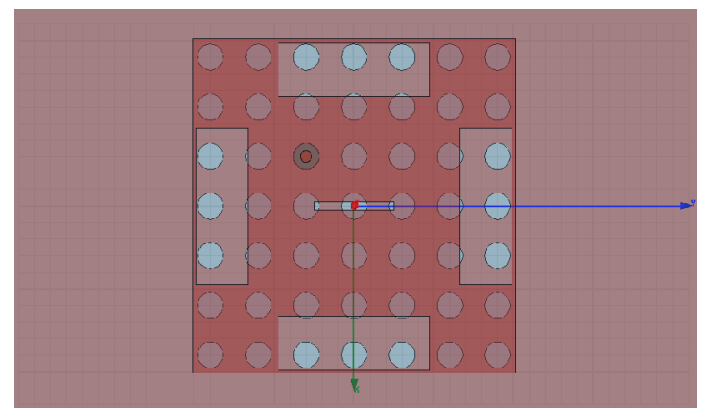

(d)

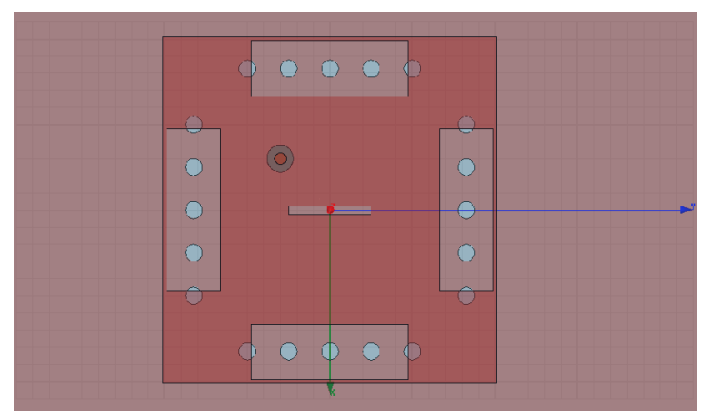

(f)

Figure (3): (a) reference patch without EBG, (b) EBG around patch, (c) $E B G$ is under patch and beyond it, (d) EBG under the patch only, (e) Staggered EBG under the patch, (f) EBG under dual-freq. slots. 
Most of the conducted research in 1D_EBG and 2D-EBG structures for antenna enhancement is concerned with the shape of the individual element of the periodic EBG array such as circle, square, star, H-shaped, I-shaped [9]. However, this paper gives a great attention to the position of the array of periodic simple circular etched elements with respect to the patch antenna. The simple etched circle element is used in order not to disturb the coaxial feeding mechanism. The reference patch without any defects in its ground plane is given in Figure 3(a). Figure 3(b) shows EBG structures etched on the ground plane around the patch. Figure 3(c) shows a regular EBG structure under the whole patch and beyond. Figure 2(d) shows an EBG structure under the patch only. Figure 3(e) is like 3(d) but with staggered shape changing the direction of periodicity. Finally, Figure 3(f) shows separate 1D-EBG structures concentrated under the dualfrequency slots only.

A 3D model is built for each configuration of Figure 3 using Ansoft HFSS to predict antenna parameters for each case. For all configurations, the radius of etched circular elements " $\mathrm{r}$ " and the periodic center to center distance "a" are kept constant to make an initial prediction for the best structure.

\subsection{Choice of a suitable PBG structure}

Table 1 shows a comparison of the simulation results obtained from the patch antennas with different EBG distributions as given in Figure 3. The main simulated parameters are:

First: the return loss $\mathrm{RL}$ in $\mathrm{dB}$, and voltage standing wave ratio VSWR to check the 10 $\mathrm{dB}$ operating frequency bandwidth of the low and high sub-bands; BW1 and BW2 respectively. The return losses for the low and high sub-bands are referred to as $\mathrm{RL}_{1}$ and $\mathrm{RL}_{2}$ correspondingly. The VSWR of the low and high sub-bands are also referred to as $\mathrm{VSWR}_{1}$ and $\mathrm{VSWR}_{2}$ respectively.

Second: the axial ratio AR to check for the circular polarization purity; AR should be less than $3 \mathrm{~dB}$.

Third: Antenna gain in $\mathrm{dBi}$.

Fourth: Half power beam width HPBW in degrees.

The optimum value for each parameter is shaded as shown in Table 1. It is clear that the configuration of Figure 3 (f), the one with EBG structures concentrated under the dualfrequency slots gives better parameter values than other configurations. Although it does not obtain the best values for return loss at the first frequency $\left(\mathrm{RL}_{1}\right)$ and antenna gain, it has the best values for other parameters. Also, it should be noticed that the configuration of figure 3(b) and Figure 3(c) are rejected because of their out of range axial ratio (AR). Therefore, the configuration of Figure 3(f) is chosen for the rest of the paper, to be parametric analyzed, optimized, fabricated and measured. 
Table (1): Comparison for different kind of $P B G$

\begin{tabular}{|c|c|c|c|c|c|c|}
\hline Parameters & $\begin{array}{c}\text { patch } \\
\text { without } \\
\text { EBG }\end{array}$ & $\begin{array}{c}\text { EBG } \\
\text { around } \\
\text { patch }\end{array}$ & $\begin{array}{c}\text { EBG is } \\
\text { under } \\
\text { patch and } \\
\text { beyond it }\end{array}$ & $\begin{array}{c}\text { EBG is } \\
\text { under patch } \\
\text { only }\end{array}$ & $\begin{array}{c}\text { EBG is } \\
\text { under } \\
\text { patch but } \\
\text { staggered }\end{array}$ & $\begin{array}{c}\text { EBG } \\
\text { under } \\
\text { dual-freq. } \\
\text { slots }\end{array}$ \\
\hline 3D Model & Fig.3(a) & Fig.3(b) & Fig.3(c) & Fig.3(d) & Fig.3(e) & Fig.3(f) \\
\hline $\mathbf{f}_{l}[\mathbf{G H z}]$ & 2.25 & 2.25 & 2.25 & 2.25 & 2.25 & 2.25 \\
\hline $\begin{array}{c}\mathrm{BW}_{1} \\
{[\mathrm{MHz}, \%]}\end{array}$ & $35,1.5$ & $25,1.1$ & $40,1.78$ & $40,1.78$ & $30,1.33$ & $40,1.78$ \\
\hline $\mathbf{f}_{h}[\mathbf{G H z}]$ & 3.01 & 3.01 & 3.01 & 3.01 & 3.01 & 3.01 \\
\hline $\begin{array}{c}\mathbf{B W}_{2} \\
{[\mathrm{MHz}, \%]}\end{array}$ & $25,0.83$ & $10,0.33$ & $25,0.83$ & $25,0.83$ & $10,0.33$ & $25,0.83$ \\
\hline $\mathrm{RL}_{1}[\mathrm{~dB}]$ & -18 & -12.73 & -20.5 & -18.82 & -17.64 & -16.13 \\
\hline $\mathrm{RL}_{2}[\mathrm{~dB}]$ & -20 & -11.72 & -25.62 & -25.28 & -17.58 & -26.96 \\
\hline Gain [dBi] & 6.9 & 7.25 & 7.01 & 7.13 & 6.99 & 7.07 \\
\hline $\mathrm{AR}$ [dB] & 2.4 & 6.5 & 3.95 & 2.23 & 2.08 & 1.9 \\
\hline VSWR & $1.3,1.27$ & $1.65,1.76$ & $1.27,1.12$ & $1.3,1.16$ & $1.34,1.34$ & $1.25,1.15$ \\
\hline $\begin{array}{c}\text { HPBW } \\
\text { [degree] }\end{array}$ & 90 & 86 & 86 & 88 & 92 & 94 \\
\hline
\end{tabular}

\subsection{Parametric analysis of the proposed under slot EBG patch antenna}

For EBG configuration, there are two important parameters; namely the radius of etched circular elements and the periodic center to center distance. For another under slot case, it was mentioned that an optimal design should satisfy the following relation between "a" and " $\mathrm{r}$ " [12]:

$$
0.1 \prec r / a \prec 0.2
$$

In this subsection, a parametric analysis is performed for both "a" and " $r$ ". First, the radius " $\mathrm{r}$ " is varied while maintaining "a" as $10 \mathrm{~mm}$. The 3D EM simulations are obtained and compared as shown in Figure 4. Second, the period "a" is varied while maintaining " $\mathrm{r}$ " as $1 \mathrm{~mm}$. The 3D EM simulations are obtained and compared as shown in Figure 5. It is clear from Figure 4 that $r=1 \mathrm{~mm}$ is the optimum, while Figure 5 shows that $a=5 \mathrm{~mm}$ is the optimum. Therefore, the optimum 3D model will be analyzed in details as shown in the next section. 


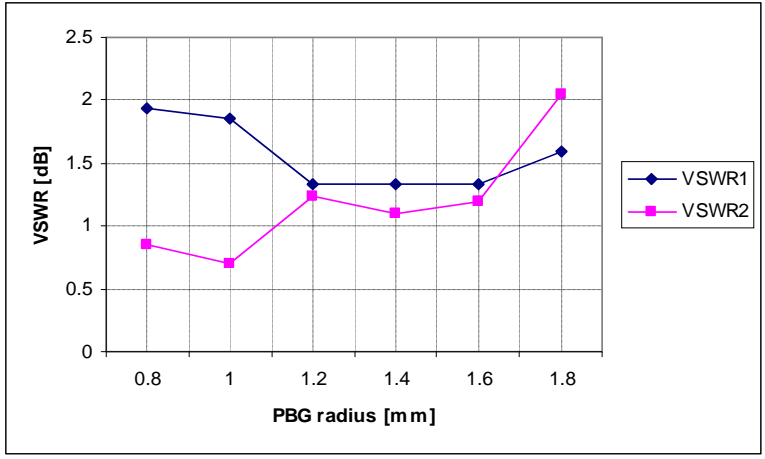

(a)

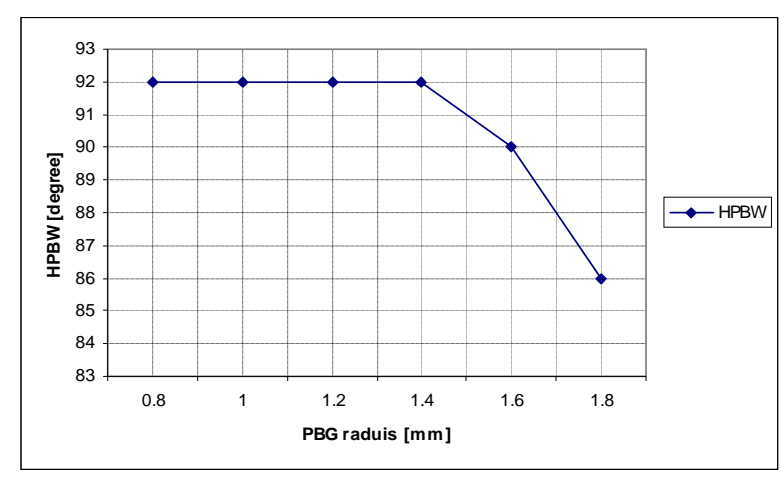

(c)

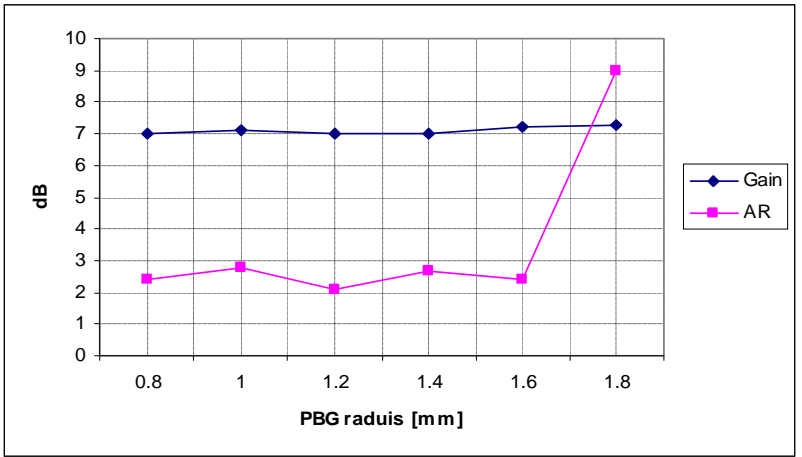

(b)

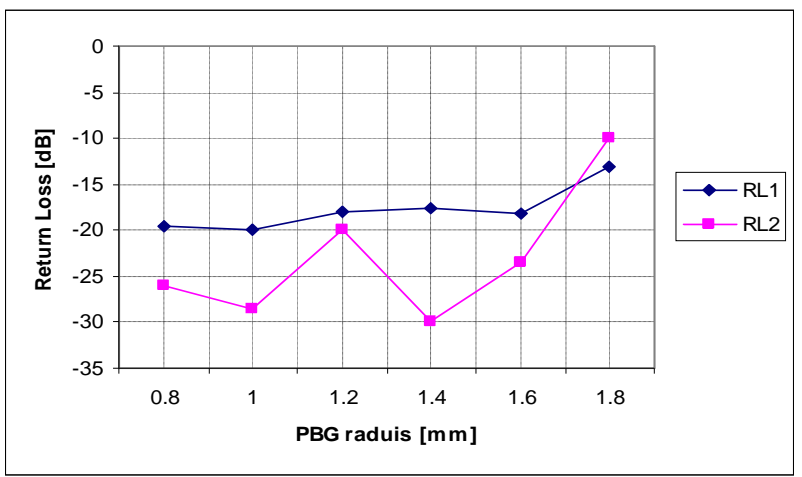

(d)

Figure (4): parametric analysis at $a=10 \mathrm{~mm}$ for different values of $r$ (a) VSWR, (b) Gain in dBi and AR in dB, (c) HPBW, (d) Return Loss.

\section{Final Optimized Design of a Dual-band patch antenna using EBG structure under the dual frequency slots:}

As seen in last section, the final chosen parameters are $r=1 \mathrm{~mm}$ and $\mathrm{a}=5 \mathrm{~mm}$. The $3 \mathrm{D}$ patch antenna model with these parameters is shown in Figure 6(a). Its top view is shown in Figure 6(b) with the simulated electric field magnitude. While, Figure 7 plots the magnetic field vectors. The dual frequency operation is verified using the return loss simulation as illustrated in Figure 8. The circular polarization purity is verified in Figure 9 which shows axial ratio below $3 \mathrm{~dB}$ along theta from -60 to 60 degrees approximately for both $\mathrm{phi}=0^{\circ}$ and $\mathrm{phi}=90^{\circ}$ planes. Figure 10 shows the radiation pattern for both $\mathrm{phi}=0 \circ$ and $\mathrm{phi}=90^{\circ}$ planes. Finally, this work is compared to the reference antenna without EBG of [8] and some other published dual band circularly polarized patch antennas as in [10] and [11]. This comparison is given in Table (2), which proves that the proposed antenna has an outstanding parameters compared to other reported microstrip antennas and has better performance than the one without EBG. The values of enhancement over the 
reference patch of [8] are shaded in Table (2).

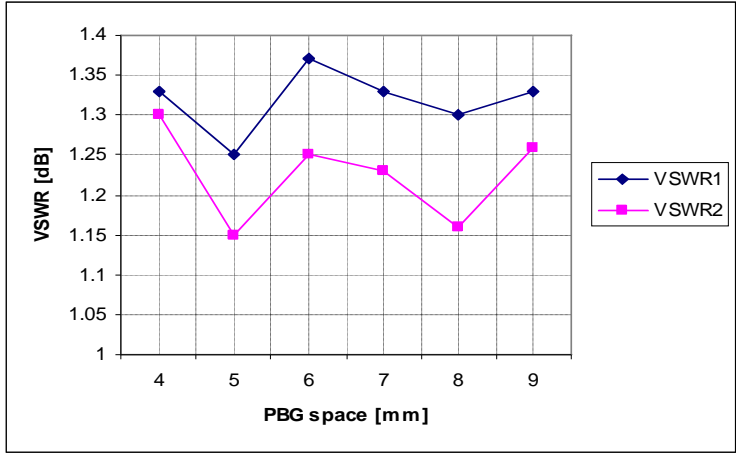

(a)

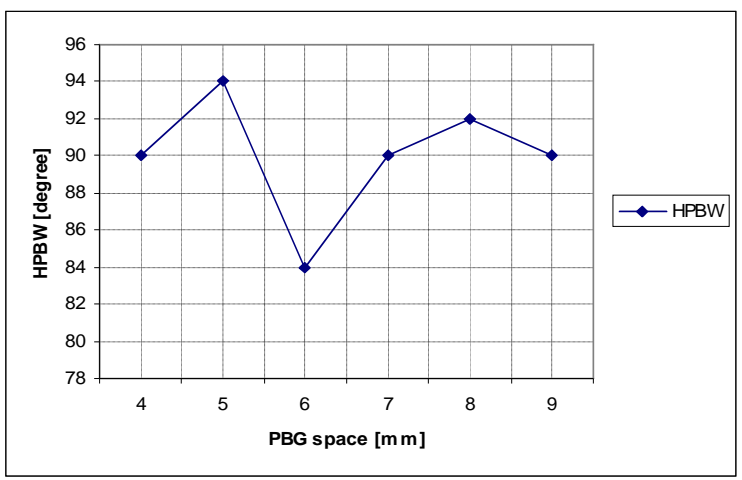

(c)

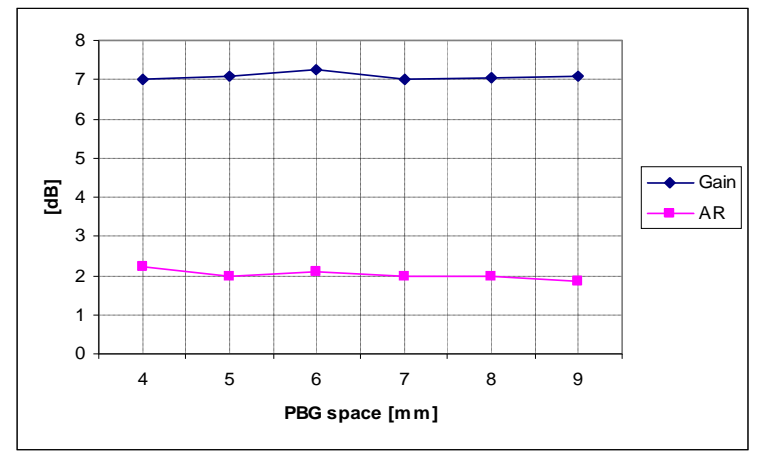

(b)

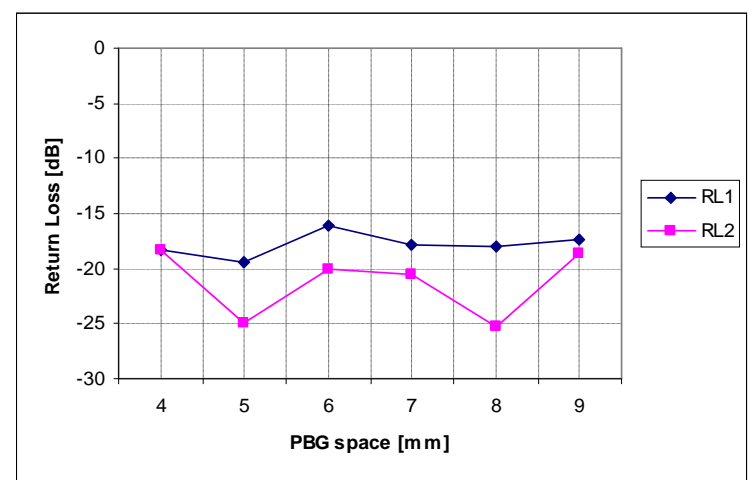

(d)

Figure (5): Parametric analysis at $r=1 \mathrm{~mm}$ for different values of a (a) VSWR, (b) Gain in dBi and AR in dB, (c) HPBW, (d) Return Loss.

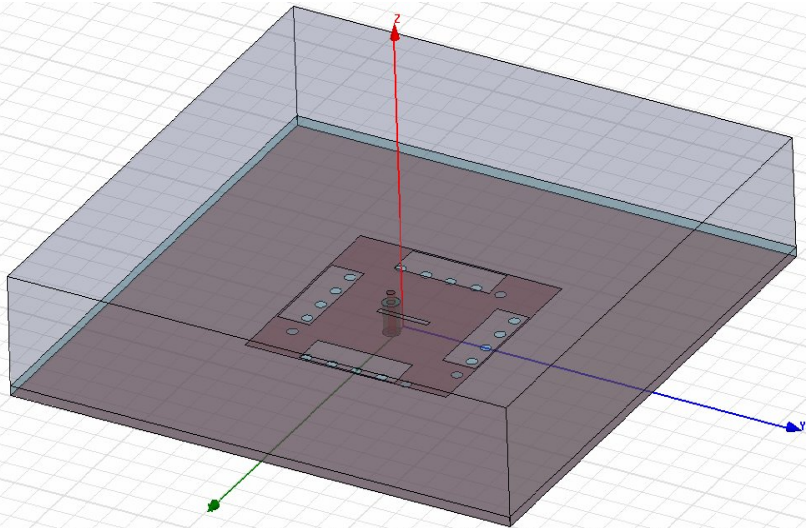

(a)

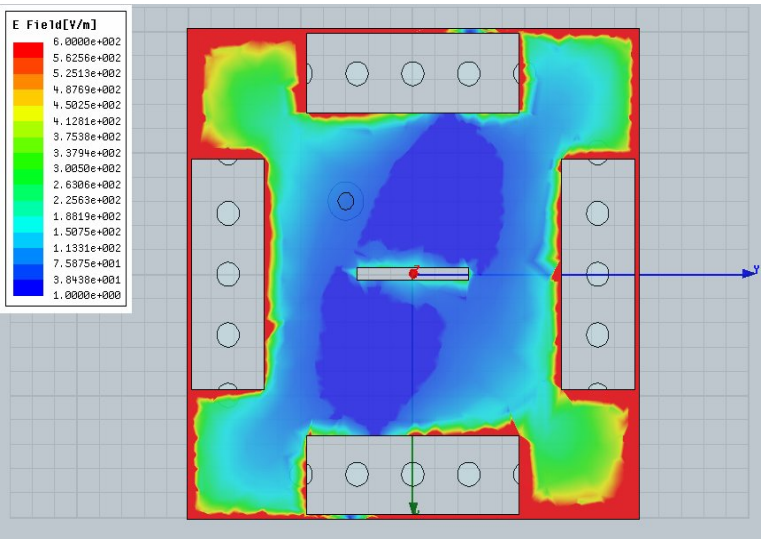

(b)

Figure (6): (a) 3-D EM model of the final design

(b) Top view showing the electric field magnitude distribution 
Proceedings of the $7^{\text {th }}$ ICEENG Conference, May, 2010

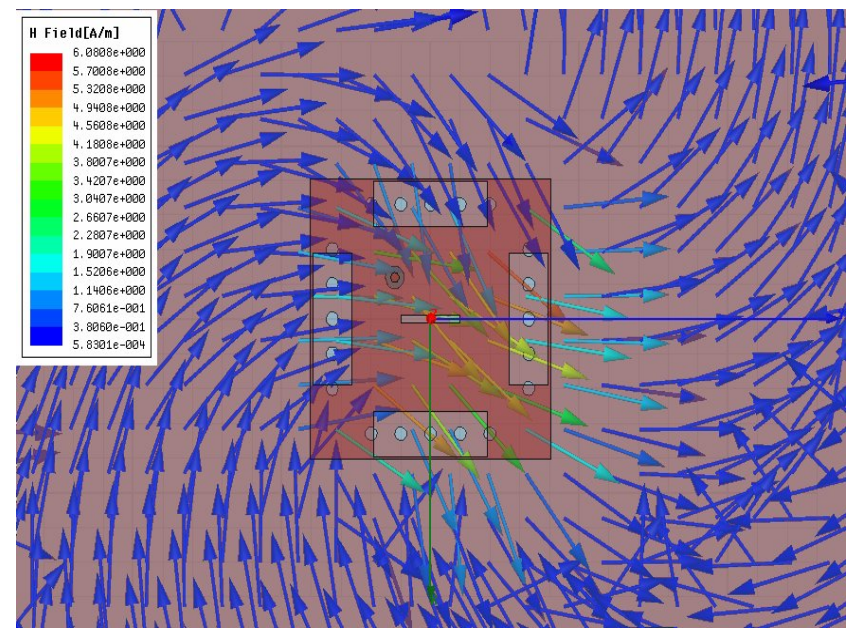

(a)

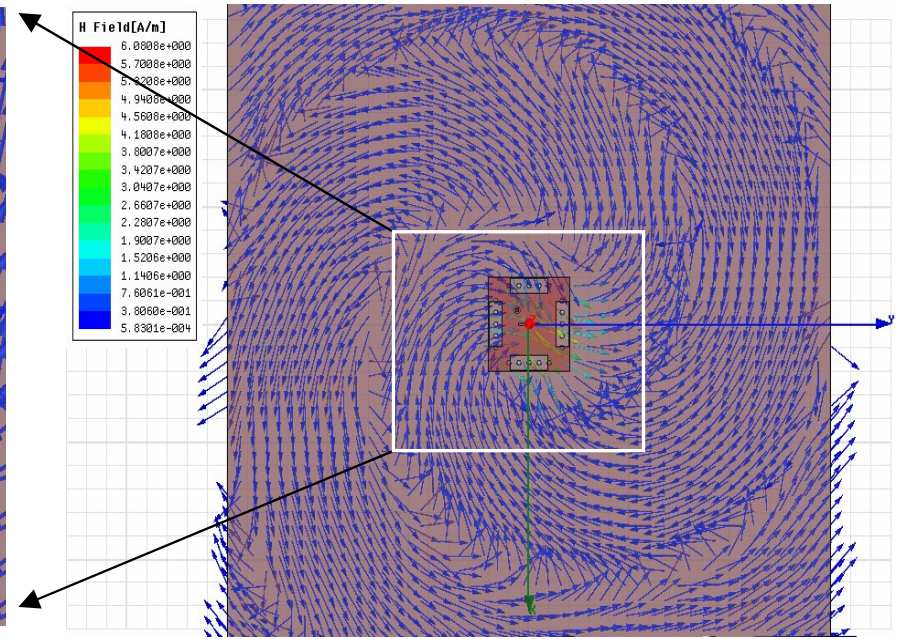

(b)

Figure (7): Plot of the Magnetic field vectors

(a) zoom-in view, (b) zoom-out view

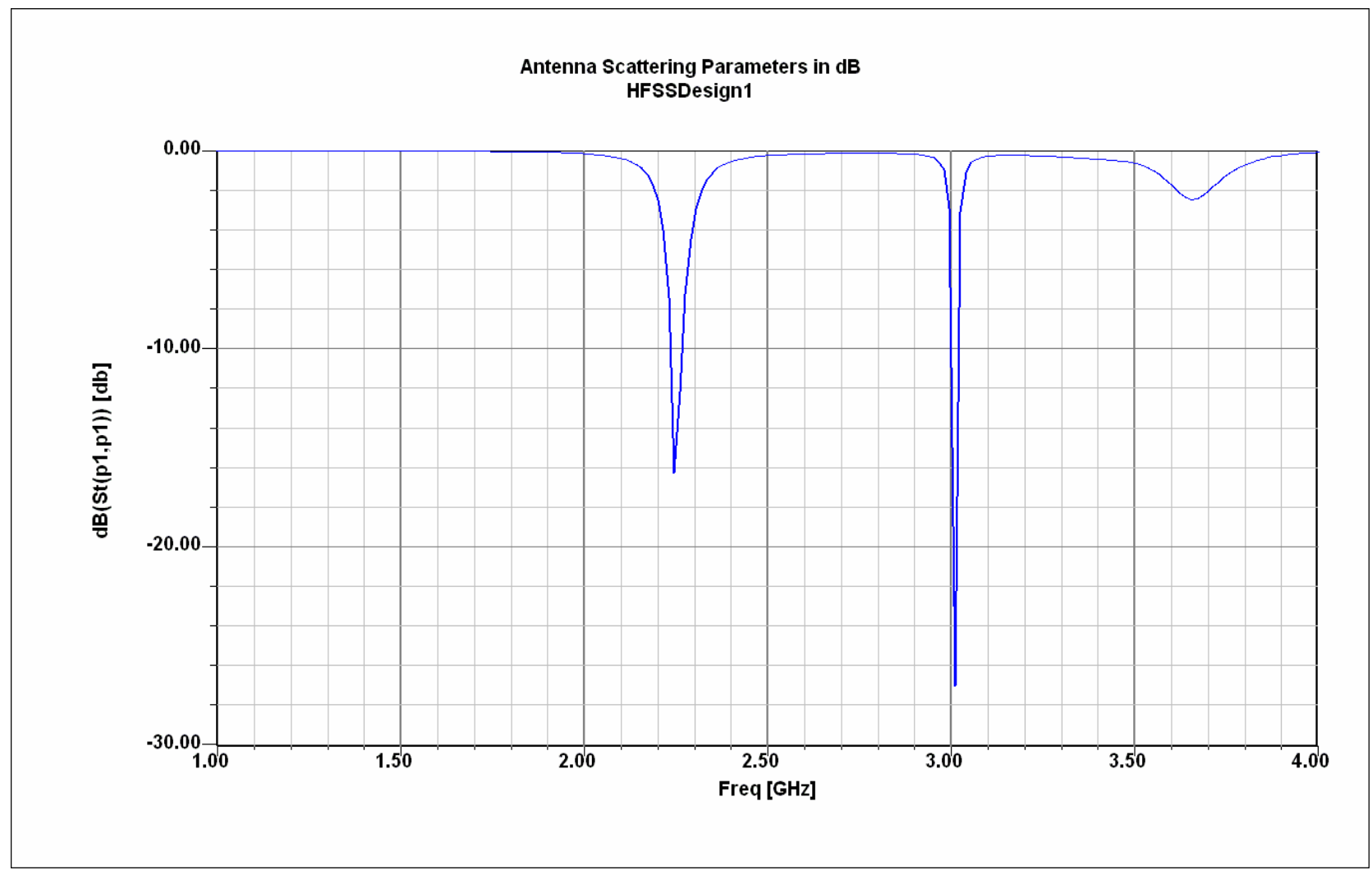

Figure (8): $S 11$ parameters in $d B$ 


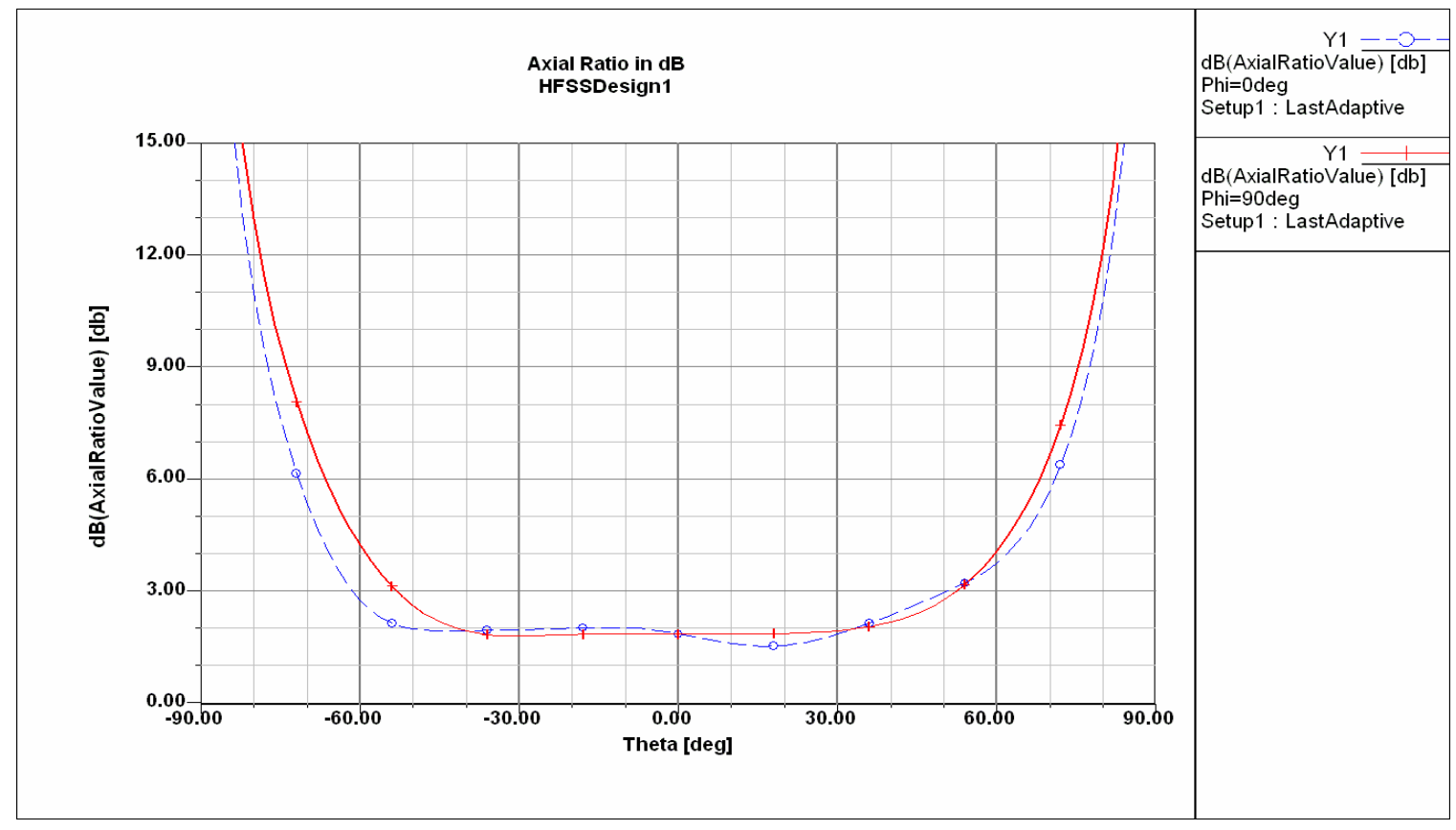

Figure( 9): Axial ratio in $\mathrm{dB}$ versus Theta in degree

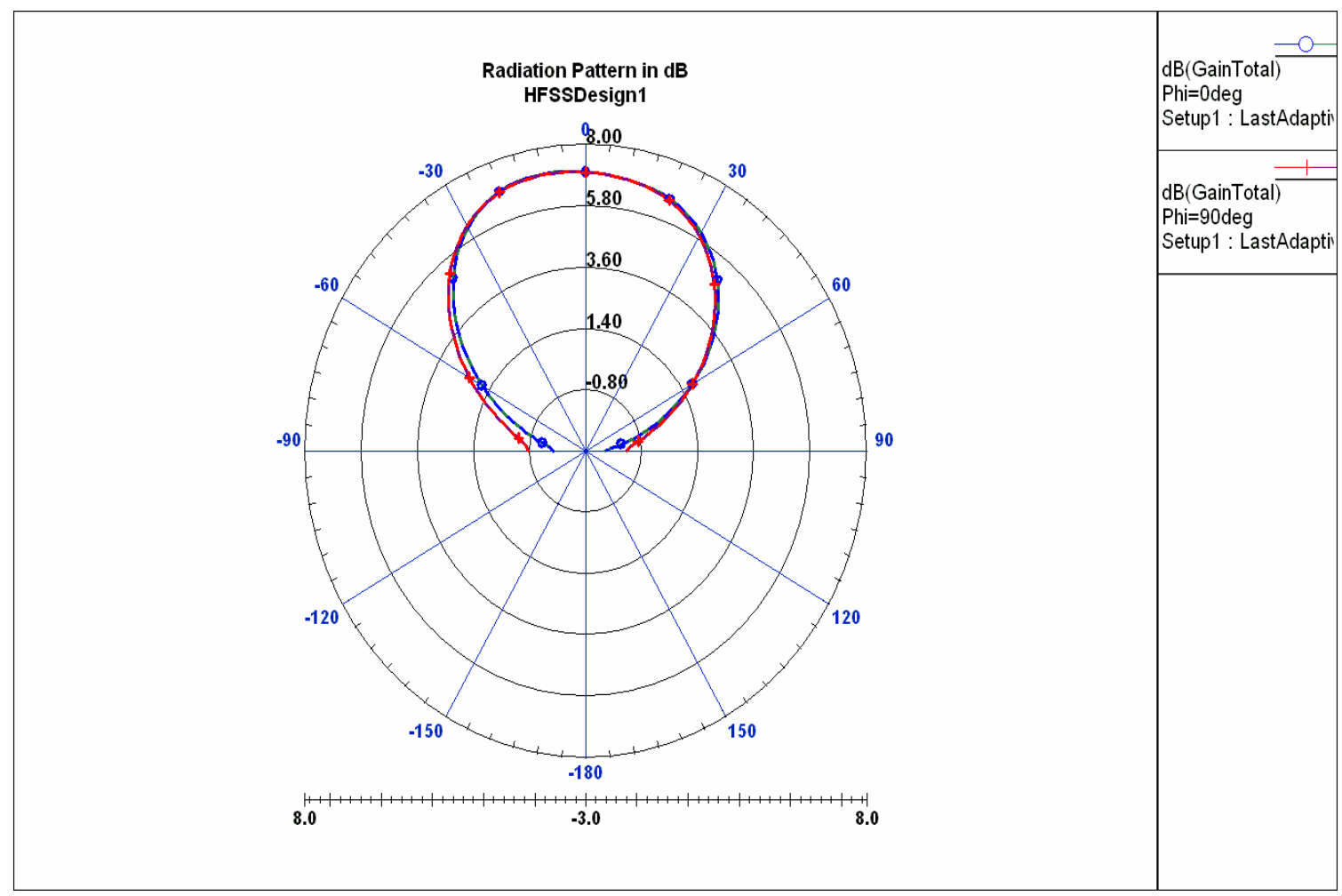

Figure (10): Polar Radiation pattern of the gain in [dBi] 
Table (2): Comparison for different kind of antenna

\begin{tabular}{|c|c|c|c|c|c|}
\hline Parameters & $\begin{array}{c}\text { Patch of } \\
\text { [10] }\end{array}$ & $\begin{array}{c}\text { Patch of } \\
\text { [11] }\end{array}$ & $\begin{array}{c}\text { Reference } \\
\text { patch } \\
\text { without } \\
\text { EBG [8] }\end{array}$ & $\begin{array}{c}\text { patch with } \\
\text { under-slot } \\
\text { EBG } \\
\text { [ This Work] }\end{array}$ & $\begin{array}{c}\text { Enhancement } \\
\text { Value over } \\
{[8]}\end{array}$ \\
\hline$f_{l} G H z$ & 1.227 & 1.19 & 2.25 & 2.25 & -- \\
\hline$B W_{1} \quad[M H z, \%]$ & $24,1.9$ & $20,1.6$ & 40 & $40,1.78$ & \\
\hline$f_{h} G H z$ & 1.575 & 1.65 & 3.01 & 3.01 & -- \\
\hline$B W_{2} \quad[M H z, \%]$ & $24,1.52$ & $20,1.2$ & 20 & $25,0.83$ & $5 \mathrm{MHz}$ \\
\hline$R L_{l}[d B]$ & -24 & -23 & -22 & -16.4 & $+5.6 d B$ \\
\hline$R L_{h}[d B]$ & -11 & -14 & -21 & -27 & $-6 d B$ \\
\hline Gain [dBi] & N.A. & 6.7 & 6.9 & 7.08 & $0.18 d B$ \\
\hline Patch Size $\left[\mathrm{mm}^{2}\right]$ & $54 * 54$ & $99 * 99$ & $40.6 * 40.6$ & $40.6 * 40.6$ & -- \\
\hline$A R[d B]$ & 2 & 1 & 2.45 & 1.89 & $-0.56 d B$ \\
\hline$\varepsilon_{r}$ & 2.6 & $2.2,1$ & 2.2 & 2.2 & -- \\
\hline$h[\mathrm{~mm}]$ & 2.4 & $0.6,5$ & 1.6 & 1.6 & -- \\
\hline HPBW [degree] & N.A. & $\sim 60$ & 90 & 94 & $4 \square$ \\
\hline
\end{tabular}

\section{Fabrication and Measurements:}

The proposed antenna element is fabricated using photolithography technique on a microstrip substrate. The fabricated prototype is shown in Figure 11. The return loss is measured using HP8510c vector network analyzer. Figure 12 compares between measured and simulated results. It shows good agreement between both, which verifies design and optimization methodology. One can notice some discrepancy between measured and simulated results which may be related to etching errors in fabrication phase and coaxial probe feeding in assembly phase.

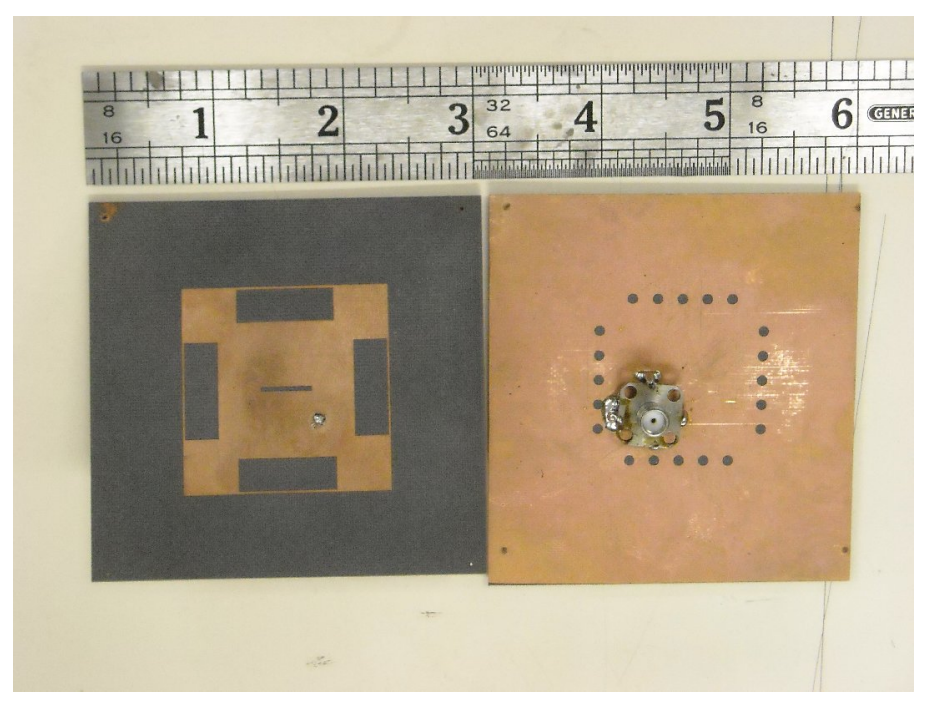

Figure (11): Photograph of the fabricated prototype 


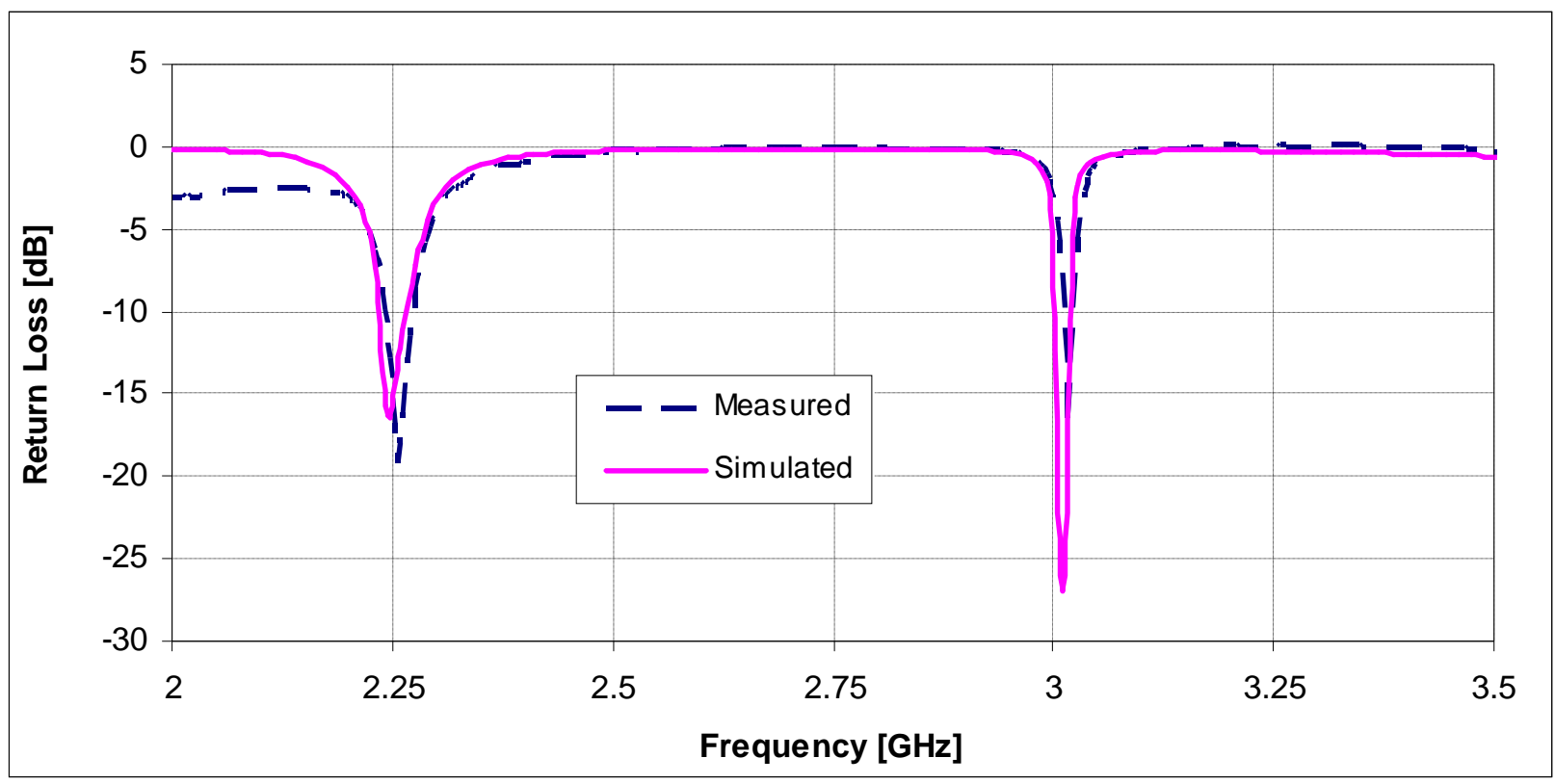

Figure (12): Measured versus simulated $S_{11}$ of the proposed antenna element

\section{5-Conclusion:}

In this paper, a novel circularly polarized, dual-frequency, slotted square patch is designed, implemented and measured using etched circular 1D-EBG structures in ground plane under the dual-band slots with probe feeding mechanism to operate at $2.25 \mathrm{GHz}$ and $3 \mathrm{GHz}$. This paper gives a great attention to the position of the array of periodic elements with respect to the patch antenna. Therefore, five different schemes of periodic defects are applied to its ground plane and compared using 3D EM simulation. The one with periodic etched circles under the dual frequency slots is found to be the best. Hence, a parametric analysis is performed to obtain the optimum EBG periodic dimensions. It exhibits superior performance enhancement compared to the same antenna that was designed and optimized without applying EBG structure. The enhancement in its performance is noticed as $2.6 \%$ higher gain, $25 \%$ wider bandwidth, better $22 \%$ axial ratio. Measurements are in good agreement with simulations, which verifies the design procedure and strongly recommends the proposed element for telemetry, telecommand and control (TT\&C) satellite antenna systems.

\section{References:}

[1] E. Brown, C. Parker, and E. Yablonovitch, "Radiation Properties of a Planar Antenna on a Photonic-Crystal Substrate," J. Opt. Soc. Am. B, vol. 10, No. 2, Feb. 1993, pp. 404-407.

[2] Y. Rahmat-Samii and H. Mosallei, "Electromagnetic band-gap structures: classification, characterization, and applications," $11^{\text {th }}$ Int. Conf., Antennas and Propagation 2001, pp. 560564. 
[3] Y. Horii and M. Tsutsumi "Harmonic control by photonic bandgap on microstrip patch antenna," IEEE Microwave Guided Wave Letters, Vol. 9, No. 1, Jan. 1999, pp.13-15.

[4] P.S. Hui and A. Alphons "Microstrip patch antenna with annular ring PBG," Asia Pacific Microwave Conference 2000, PP. 1347-1351.

[5] Y. Hao and C.G. Parini "Isolation enhancement of PBG microstrip diplexer patch antenna," $11^{\text {th }}$ Int Conf on Antennas and Propagation, 2001, pp. 86- 89.

[6] R. Coccioli, F.R. Yang, K. Ping Ma, and Itoh "Aperature-coupled patch antenna on UC-PBG substrate," IEEE Trans Microwave Theory Tech 47, 1999, pp. 2123-2130.

[7] D. Sievinpiper, L. Zhang, R. F. G. Broas, R. G. Alexopolous and E. Yablonovitch "High impedance electromagnetic surfaces with a forbidden frequency band," IEEE Trans Microwave Theory Tech, Vol. 47, 1999, pp. 2059-2074.

[8] A. M. Eltager, M. A. Eleiwa, and M. I. Salama "A Circularly Polarized Dual-Frequency Square Patch Antenna for TT\&C Satellite Applications," PIERS Proceedings, pp. 523-527, March 23-27, Beijing, CHINA 2009.

[9] D. Elsheakh, M. Iskander, E. Abdallah, H. Elsadek, and H. Elhenawy " Microstrip Array Antenna With New 2D-Electromagnetic Band Gap Structure Shapes To Reduce Harmonics And Mutual Coupling," Progress in Electromagnetic Research C, Vol. 12, 2010, pp. 203-213.

[10] F. Takafumi, I. Kouhei, and T. Mitsuo "Dual band circularly polarized microstrip antenna for GPS application," IEEE Antennas and Propagation society International Symposium, 2008.

[11] A. A. Heidari, M. Heyrani, and M. Nakhkash "A dual-band circularly-polarized stub loaded microstrip patch antenna for GPS applications," Progress In Electromagnetics Research, PIER 92, 2009, pp. 195-208.

[12] H. Sabri and Z. Atlasbaf "Two novel compact triple-band microstrip annular-ring slot antenna for PCS-1900 and WLAN application," Progress In Electromagnetics Research Letters, Vol. 5, pp. 87-98, 2008. 